
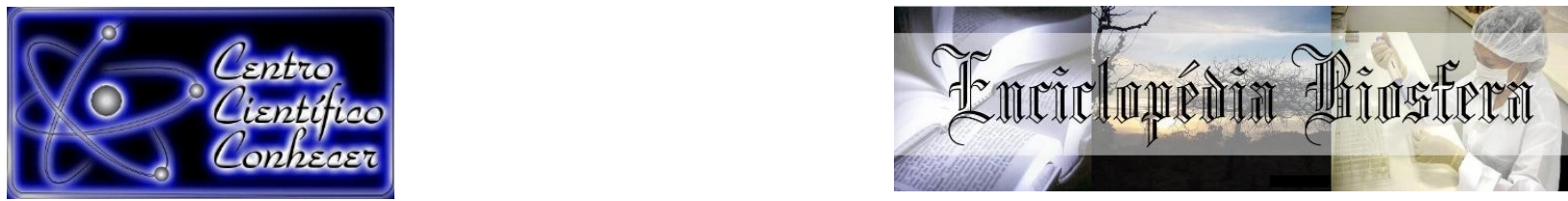

\title{
PLANTAS ORNAMENTAIS TÓXICAS EM ESCOLAS DE ENSINO FUNDAMENTAL NO MUNICÍPIO DE ALTAMIRA, PARÁ
}

Dhyene Rayne Silva Dos Santos ${ }^{1}$; Maristela Marques Da Silva²;

${ }^{1}$ Acadêmica do curso de Engenharia Agronômica, da Universidade Federal do Pará, campus Altamira, R. Cel. José Porfírio, 2515 - São Sebastião, Altamira - PA, 68371040. Drayneagro@gmail.com

${ }^{2}$ Docente pesquisadora da Faculdade de Engenharia Agronômica da Universidade Federal do Pará, Campus Universitário de Altamira.

Recebido em: 15/02/2020 - Aprovado em: 15/03/2020 - Publicado em: 30/03/2020

DOI: 10.18677/EnciBio_2020A15

\begin{abstract}
RESUMO
As plantas ornamentais trazem a sensação de bem-estar e que embelezam os ambientes, entretanto, por trás dessa beleza pode existir na sua constituição química, elementos tóxicos à espécie humana e animais. Este estudo tem como objetivo realizar um levantamento a respeito de plantas ornamentais tóxicas presentes em escolas no município de Altamira, Pará. A pesquisa foi realizada em Abril de 2016 em 20 escolas públicas de ensino fundamental que representa $53 \%$ do total de escolas urbanas. Com o levantamento realizado observou-se que $70 \%$ dos estabelecimentos apresentaram plantas tóxicas. Nas escolas foram identificadas 15 espécies tóxicas, destacando-se entre as mais abundantes as espécies conhecidas popularmente como comigo-ninguém-pode (Dieffenbachia picta Schott.) e tinhorão (Caladium bicolor Vent.) pertencentes à família Araceae.
\end{abstract}

PALAVRAS-CHAVE: Araceae; Espécies Tóxica; Intoxicação.

\section{TOXIC ORNAMENTAL PLANTS IN FUNDAMENTAL SCHOOLS IN ALTAMIRA, PARA}

Ornamental plants bring a feeling of well-being and that embellish the environments, however, behind this beauty there may be in its chemical constitution, elements toxic to the human species and animals. This study aims to carry a survey about toxic ornamental plants present in schools in the municipality of Altamira, Para. The research carried out in April 2016 in 20 public elementary schools representing 53\% of the total urban schools. With the survey carried out it observed that $70 \%$ of the establishments had toxic plants. In schools, 15 toxic species identified, among which the species known popularly as me-nobody-can (Dieffenbachia picta Schott.) and tinhorao (Caladium bicolor Vent.) Belonging to the Araceae family stand out.

KEYWORDS: Araceae; species toxic; poisoning; 


\section{INTRODUÇÃO}

Plantas ornamentais são plantas cultivadas por sua beleza, estão próximas ao homem, de fácil acesso e que embelezam os locais de cultivo. Porém, muitas vezes por trás de tanta beleza, podem esconder um grande perigo em sua constituição química, com a presença de elementos tóxicos aos homens e animais (SILVA et al., 2014). As plantas ornamentais diferenciam-se pela forma, florescimento, cor das folhas e folhes e aspecto geral da planta. Com a presença de elementos tóxicos, muitas dessas plantas são categorizadas como plantas tóxicas, e podem causar transtornos principalmente as crianças (LORENZI, 2002; TEXEIRA; LIMA, 2020).

É importante ressaltar que muitas pessoas que manuseiam plantas ornamentais não tem o conhecimento sobre a composição química presente nessas plantas e acabam utilizando apenas por ser bonita e de fácil manejo, porém essas plantas podem ocasionar vários danos quando manejados de forma incorreta.

Segundo Silva et al., (2017) as plantas tóxicas possuem substâncias químicas que podem ocasionar nos organismos sintomas de intoxicação, conduzindo a reações diversas como queimaduras, vermelhidão e irritação na pele, boca ou olhos, podendo levar a óbito.

De acordo Silva (2009), as crianças são as principais afetadas e extremamente vulneráveis as plantas tóxicas, pois elas na curiosidade de explorar tudo a sua volta acabam sofrendo inúmeras lesões ao manejarem imprudentemente tais vegetais. Para isso, é necessário um certo conhecimento das espécies apropriadas para cada ambiente, principalmente quando relacionado ao ambiente escolar, onde a presença de crianças é constante, desse modo as mesmas podem manipular essas plantas e provocar acidentes com intoxicação.

Por se tratar de um ambiente que tem uma grande presença de crianças se faz necessário o estudo especifico sobre as plantas ornamentais presentes, para um melhor conhecimento dos vegetais, auxiliando no planejamento das espécies e auxiliando para a prevenção de intoxicações por espécies desconhecidas pela escola.

Neste contexto, este trabalho teve como objetivo realizar um levantamento a respeito de plantas ornamentais tóxicas presentes em escolas públicas de ensino fundamental no município de Altamira, Pará.

\section{MATERIAL E MÉTODOS}

O município de Altamira está localizado no Sudoeste do Estado do Pará, com sede municipal possuindo as seguintes coordenadas geográficas: $03^{\circ} 13^{\prime}$ de latitude sul e $52^{\circ} 13^{\prime}$ de longitude oeste de Greenwich.

A pesquisa foi realizada em Abril de 2016 em 20 escolas públicas de ensino fundamental do município de Altamira (PA), as escolas visitadas representam 53\% do total de escolas urbanas do município. Inicialmente foram realizadas entrevistas com os responsáveis das escolas com a aplicação de um questionário estruturado, abordando aspectos ligados a caso de intoxicação na escola e os cuidados com as plantas presentes na área externa da escola. Após a entrevista foi realizada uma turnê na área externa de cada escola, com o objetivo de a presença de plantas com o potencial de serem tóxicas.

As espécies com potencial de serem consideradas tóxicas foram fotografadas e coletadas para serem herborizadas e identificadas no Laboratório de Botânica da Faculdade de Engenharia Agronômica da Universidade Federal do Pará, Campus Altamira. As famílias botânicas das angiospermas foram classificadas de acordo com o sistema proposto pelo APG (Angiosperm Phylogeny Group) III. Epítetos 
específicos, autorias das espécies e sinonímias foram conferidas por meio das bases online da Flora do Brasil 2020 (http://floradobrasil.jbrj.gov.br/).

\section{RESULTADOS E DISCUSSÃO}

Das 20 escolas visitadas pela pesquisa, em 30\% das escolas não foram identificadas a presença de plantas tóxicas, porém $70 \%$ das instituições de ensino apresentaram tais vegetais com uma média de três espécies diferentes por estabelecimento (Figura 1).

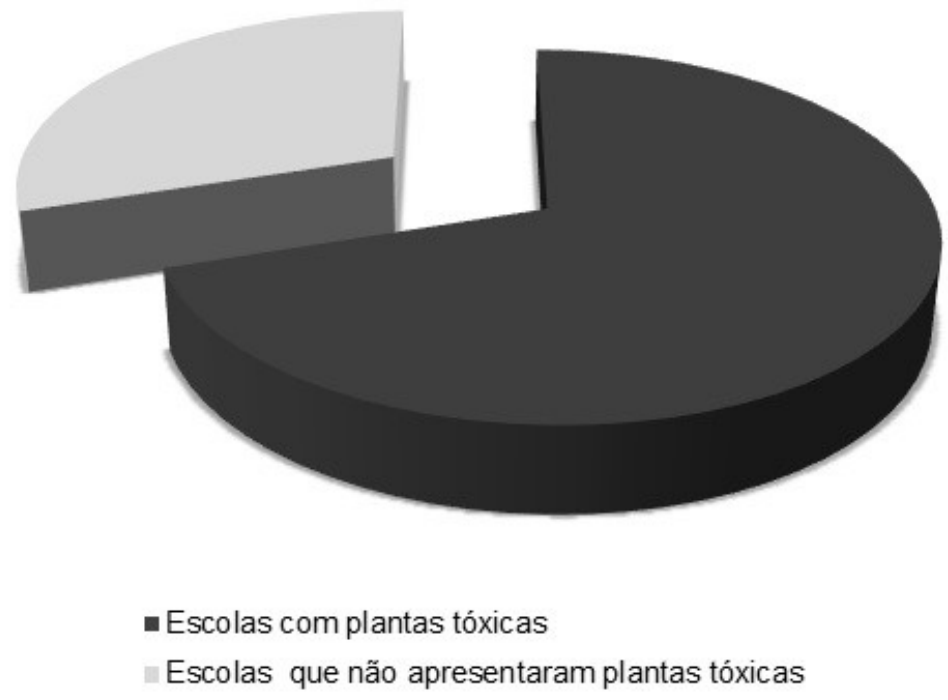

FIGURA 1: Percentagem das escolas de ensino fundamental no que apresentaram plantas tóxicas no município de Altamira.

O número de escolas que apresentou plantas tóxicas é considerado alto, isso deve deixar em alerta os responsáveis das escolas para possíveis casos de intoxicação. Em outros estudos desenvolvidos em escolas, a incidência de plantas tóxicas, nas áreas externas das escolas também foram significativos (BOCHNER et. al., 2013; FOOK et. al 2014; BRAGA et al., 2017).

Nas escolas com presença de plantas tóxicas foram identificados 60 indivíduos, abrangendo 15 espécies, distribuídas em oito famílias botânicas, que segundo a bibliografia consultada são consideradas tóxicas. A família Araceae apresentou maior número de indivíduos com 52\%, seguida pela Liliaceae e Euphorbiaceae que se destacou com $13 \%$ (Figura 2).

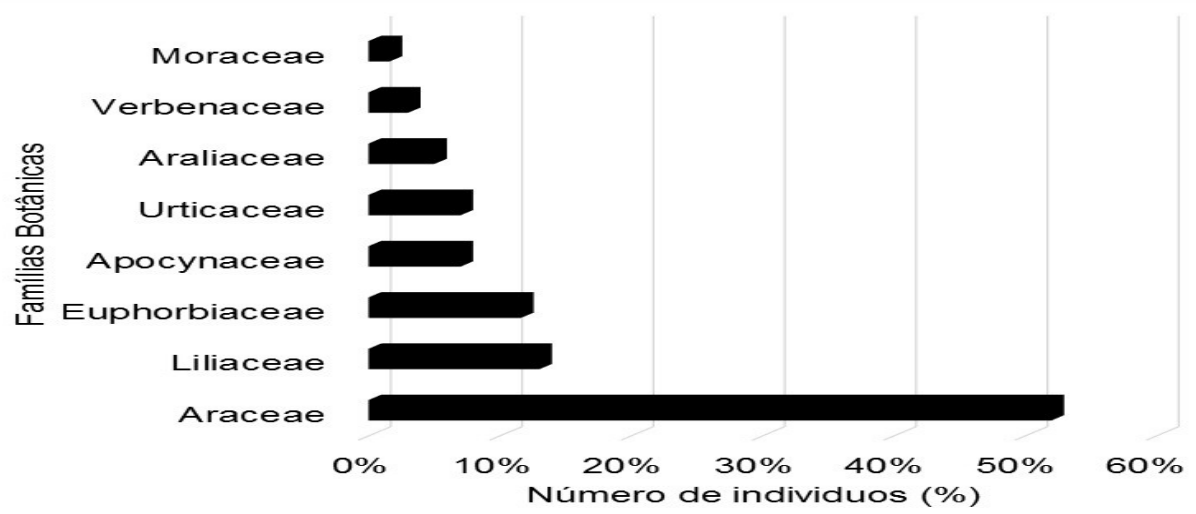

FIGURA 2: Famílias botânicas identificadas nas escolas de Altamira. FONTE : AUTORES 
A família Araceae é muito utilizada para uso ornamental, devido a diversidade de espécies com folhagem coloridas. Dessa forma é bastante comum ser encontrada ambientes escolares. No município de Altamira, em estudos desenvolvidos por Braga et al., (2017), a família Araceae também destacaram-se com o maior número de indivíduos. Em estudo desenvolvido por Bochner et. al., (2013) no Rio de Janeiro (RJ) e por Fook et. al. (2014) em estudo em Campina Grande (PB), a família das Araceae se destacou com um maior número de espécies consideradas tóxicas.

A maioria dos vegetais tóxicos foram encontrados nos jardins das escolas, o mesmo resultado foi obtido no trabalho de Fook et. al. (2014), onde 78\% das plantas estavam em jardins, que é o local preferido das crianças no intervalo e recreações. As plantas encontradas nas escolas foram doadas ou trazidas de casa, ou seja, a maioria das pessoas ainda não conhecem os riscos que submetem os alunos e que eles mesmos correm pela falta de conhecimento. A maior parte das escolas não possuem uma pessoa que cuide do jardim, facilitando o acesso das crianças a tais plantas.

As espécies comigo-ninguém-pode (Dieffenbachia picta Schott) $18 \%$, tinhorão (Caladium bicolor Vent.) 13\%, jiboia (Scindapsus aureus) $8 \%$, antúrio (Anthurium andraeanum Liden) $8 \%$ e taioba-brava (Calocasia antiquorum Schott) 3\%, pertencentes à família das Araceae, foram às principais espécies presentes nas instituições. Os vegetais dessa família contêm toxidade em todas as partes da planta, com presença de oxalato de cálcio que é uma substância quando ingerida pode causar vermelhidão, queimaduras, irritação e inchaços na boca e língua.

QUADRO 1: Espécies tóxicas encontradas nas 20 escolas no Município de Altamira.

\begin{tabular}{|c|c|c|c|}
\hline Família/Nome científico & Nome Comum & $\begin{array}{c}\text { Princípios } \\
\text { ativos }\end{array}$ & Número \\
\hline \multicolumn{4}{|l|}{ Araceae } \\
\hline & & Oxalato de & \\
\hline Anthurium andraeanum Liden & $\begin{array}{l}\text { Antúrio } \\
\text { Comigo- }\end{array}$ & $\begin{array}{c}\text { cálcio. } \\
\text { Oxalato de }\end{array}$ & 5 \\
\hline Dieffenbachia picta Schott & ninguém-pode & $\begin{array}{c}\text { cálcio. } \\
\text { Oxalato de }\end{array}$ & 11 \\
\hline Scindapsus aureus (Linden \& André) Engl. & Jiboia & $\begin{array}{c}\text { cálcio. } \\
\text { Oxalato de }\end{array}$ & 5 \\
\hline Calocasia antiquorum Schott & Taioba-Brava & $\begin{array}{c}\text { cálcio. } \\
\text { Oxalato de }\end{array}$ & 2 \\
\hline Caladium bicolor Vent. & Tinhorão & cálcio. & 8 \\
\hline \multicolumn{4}{|l|}{ Araliaceae } \\
\hline Schefflera arboricola((Hayata)Merr. & Chefrela & Saponinas & 3 \\
\hline \multicolumn{4}{|l|}{ Apocynaceae } \\
\hline Plumeria rubra L. & & $\begin{array}{c}\text { Alcalóide } \\
\text { agoniadina }\end{array}$ & 2 \\
\hline Thevetia peruviana (Pers.) K. Schum. & $\begin{array}{c}\text { Chapéu-de- } \\
\text { napoleão }\end{array}$ & $\begin{array}{l}\text { Tevetinas A e } \\
\mathrm{B} \text {, neriifolina. }\end{array}$ & 2 \\
\hline \multicolumn{4}{|l|}{ Euphorbiaceae } \\
\hline Codiaeum variegatum (L.) A. Juss & Cróton & $\begin{array}{c}\text { Alcaloide } \\
\text { crotina. } \\
\text { Ésteres do }\end{array}$ & 4 \\
\hline Euphorbia tirucalli L. & João Duro & forbol . & 2 \\
\hline Jatropha curcas L. & Pião-Branco & Curcina & 2 \\
\hline
\end{tabular}




\begin{tabular}{lccc}
\hline Liliaceae & Espada de São \\
Jorge & $\begin{array}{c}\text { Oxalato de } \\
\text { cálcio, } \\
\text { saponinas. }\end{array}$ & 7 \\
\hline Sansevieria trifasciata Hort ex Pain & Ficus & $\begin{array}{c}\text { Doliarina, } \\
\text { glicosídeo } \\
\text { Cianogênico }\end{array}$ & 1 \\
\hline Ficus benjamina L. & Urtiga & $\begin{array}{c}\text { Acetilcolina, } \\
\text { histamina. }\end{array}$ & 4 \\
\hline Urticaceae & Cambará & Triterpenóides. & 2 \\
\hline $\begin{array}{l}\text { Urtica dioica L. } \\
\text { Verbenaceae }\end{array}$ & & & 60 \\
\hline Lantana camara L. & & & 2 \\
\hline Total & & & \\
\hline
\end{tabular}

As espécies comigo-ninguém-pode e tinhorão são considerados por Bochner et. al. (2013), como as duas espécies mais tóxicas da família das Araceae, sendo as principais responsáveis por causar intoxicações. A Dieffenbachia picta apresenta-se como subarbusto de caule cilíndrico, folha grande com manchas branca, bastante utilizada como planta ornamental em residências, escolas e praças. Segundo Santos (2020), a ação tóxica do comigo-ninguém-pode está presente principalmente nas folhas e no caule, a intoxicação é causada pela introdução de um princípio hipersensibilizante nos tecidos, propiciada pela ação dos cristais de oxalato de cálcio, causando irritação ao entrar em contato com a membrana mucosa. $O$ tinhorão também ornamental é uma planta semi-herbácea, com folhas rajadas que contêm todas as partes da planta tóxica e causa diversos sintomas quando ingeridos, como irritação, vermelhidão e queimação na boca, provocando inchaço e bolhas na língua, e levam à dificuldade para falar.

A espada-de-são-Jorge (Sansevieria trifasciata Hort ex Pain) teve $12 \%$ de ocorrências, é uma planta facilmente encontrada em residências, praças e escolas. Segundo Bochner et. al. (2013), a planta apresenta princípio ativo de oxalato de cálcio, saponinas e substâncias hipersensibilizantes, que pode causar irritação com o contato e edemas de lábios, língua e palato e distúrbios respiratórios ingeridos.

O João-duro (Euphorbia tirucalli L.) 3\%, o Pinhão-branco (Jatropha curcas L.) $3 \%$ e o Croton (Codiaeum variegatum (L.) A. Juss) $7 \%$, foram os representantes da família das Euphorbiaceae encontradas nos estabelecimentos de ensino. As espécies dessa família têm como partes tóxicas sementes e látex. Os principais sintomas causados por estas espécies são conjuntivite, fotofobia, diminuição da acuidade visual, edema ou úlcera da córnea (BOCHNER et al., 2013). Essas plantas mesmo sendo ornamentais não devem ser cultivadas nas proximidades de residências, devendo ser evitado o contato do látex com a pele e mucosas, principalmente com os olhos, pois causa reação alérgica e inflamatória podendo levar a cegueira temporária e até mesmo permanente.

Apenas um caso de intoxicação foi identificado nas 20 escolas estudadas. Entretanto, o caso ocorreu quando a criança entrou em contato com a planta urtiga (Urtica dioica L.), que é considerada uma planta espontânea que cresce em áreas de jardins e outros locais que não realizados tratos culturais como a capina. Em $7 \%$ das instituições estudadas foi detectada a presença de urtiga, crescendo próximas as plantas ornamentais. De acordo com Bochner et al., (2013) essa espécie é uma planta herbácea com caule e folhas cobertas de pelos dos quais são partes tóxicas, 
princípio ativo de acetilcolina e histamina, e o contato com esse vegetal causa dor imediata e irritação. Por ser considerada uma planta invasora recomenda-se fazer limpezas frequentemente nos jardins para evitar riscos de intoxicação.

\section{CONCLUSÕES}

Nesse levantamento foram identificadas 15 espécies consideradas pela biografia como tóxicas. Apesar da quantidade de plantas tóxicas, houve apenas um caso de intoxicação. Entretanto, a falta de informação e conhecimento a respeito da toxidade dessas plantas pode levar a ocorrência de acidentes nas escolas.

A presença de plantas ornamentais tóxicas é muito comum em canteiros, praças e pátios de escolas, entre outros locais de acessos fáceis para crianças. Apesar da toxidade das plantas, não necessariamente estas plantas devem ser removidas, apenas identificadas informando sobre os riscos e sua real toxidade buscando a conscientização das pessoas.

\section{REFERÊNCIAS}

BRAGA, K.C.; GIESE, S.S.; PARRY, S.M. Levantamento de plantas tóxicas em escolas urbanas de Ensino Fundamental no município de Altamira. Biota Amazônica. v.7, n.2. p. 53-58, 2017. Disponível em: <DOI: http://dx.doi.org/10.18561/2179-5746/biotaamazonia.v7n2p53-58> doi: 10.18561/2179-5746.v7n2p53-58.

BOCHNER R., FISZON J. T., ASSIS M. A., Plantas tóxicas ao alcance de crianças: transformando risco em informação. Rio de Janeiro: RioBooks, 2013. 64 p.:ll.

FOOK S.M.L., SOARES Y.C., ALMEIDA C.F., ABRANTES R.B., MEIRA C.M.B.S., FEITOSA I.L.F, MARIZ S.R. Análise da ocorrência de plantas tóxicas em escolas estaduais no município de Campina Grande (PB) como estratégia na prevenção de intoxicações. Revista Saúde e Ciência On line, 2014; 3(1) 44-55. Disponível em: < http://www.ufcg.edu.br/revistasaudeeciencia/index.php/RSCUFCG/article/view/92/8> Acessado em 04 de Agosto de 2018.

LORENZI, H.; SOUZA, H. M.. Plantas ornamentais do Brasil (arbustivas herbáceas e trepadeiras). 3 Ed. Nova Odessa, São Paulo: Ed.Plantarum, 2001.1088p.

SANTOS, V. S.. $\quad$ "Comigo-ninguém-pode"; Brasil Escola. Disponível em <https://brasilescola.uol.com.br/biologia/comigo-ninguem-pode.htm>. Acesso em 11 de fevereiro de 2020.

SILVA, L. C. Plantas ornamentais tóxicas presentes no shopping Riverside Walk em Teresina - PI. REVSBAU, Piracicaba - SP, v.4, n.3, p.69-85, 2009. Disponível em: < http://silvaurba.esalq.usp.br/revsbau/artigos_cientificos/artigo84.pdf> Acessado em 07 de Agosto de 2018.

SILVA, E. I.; SANTOS, J.O.; CONCEIÇÃO, G.M. Diversidade de plantas ornamentais no centro de estudos superiores de Caxias, da Universidade Estadual do Maranhão. 2014. Disponível em: <http://www.conhecer.org.br/enciclop/ 2014a/CIENCIAS\%20BIOLOGICAS/Diversidade.pdf> Acessado em 23 de Março de 2019. 
SILVA, R. P.P.; ANTÔNIO, S. A.; CAVALCANTE, J. J.; MORAES, S.R. Plantas tóxicas em escolas e suas implicações legais em casos de intoxicação. Revista Semioses, V 11, n.04, 2017. Disponível em: <https://doi.org/10.15202/1981996x.2017 v11n4p21> doi: 10.15202/1981996x.2017v11n4p21.

TEIXEIRA, J. B. P, LIMA ,A. A. .Plantas ornamentais tóxicas: prevenção de acidentes. Disponível em:<http://www.gege.agrarias.ufpr.br/plantastoxicas/arquivos/ euphorbia\%20pulcherrima.pdf>. Acesso 10 de fevereiro de 2020. 